\title{
Educação em saúde bucal por meio da análise das embalagens de instrumentos de higiene oral
}

\author{
Education on oral health through the analysis of packages of oral hygiene products \\ Patricia Elaine Gonçalves \\ Instituição Universidade Nove de Julho - UNINOVE \\ Professora Colaboradora do curso de Odontologia da \\ Universidade Nove de Julho - UNINOVE \\ YDIA SOUZA DE OLIVEIRA \\ Resumo da Biografia Cirirgiã-dentista graduada pela Faculdade \\ de Odontologia do Centro Universitário UnirG \\ Francielly Lourenço SeIXAs \\ Instituição Universidade Nove de Julho - UNINOVE \\ Graduanda do curso de Odontologia da Universidade Nove de Julho - UNINOVE
}

\begin{abstract}
RESUMO
Educação em saúde bucal consiste na divulgação e no esclarecimento sobre a importância da saúde bucal e os meios de tê-la e mantê-la. O objetivo deste trabalho é a análise da educação em saúde bucal por meio das embalagens de instrumentos de higiene bucal infantis. Para a coleta de dados, foi elaborado e preenchido um formulário que aborda questões como características dos instrumentos, instrução e momento do uso. As respostas fechadas foram analisadas por meio de frequência e as abertas por meio de análise de conteúdo pela técnica de palavras-chave e pela temática preconizada por Bardin. ${ }^{1}$ Foram analisados 31 instrumentos de higiene bucal, sendo que, nas embalagens de escova de dente, apenas $28,6 \%$ informavam sobre a técnica de escovação, porém nenhuma mencionou a escovação da língua e/ ou das mucosas. Com relação à quantidade de dentifrício que deve ser colocada na escova, foram obtidas diversas respostas. Com isso, concluiu-se que não há padronização das mensagens de educação em saúde bucal nos produtos de higienização bucal para o público infantil, além do que se faz necessária a conscientização das empresas quanto ao papel social de seus produtos.
\end{abstract}

Palavras-chave: EDUCAÇÃo EM SAÚDE, ODONTOLOGIA PREVENTIVA, ODONTOPEDIATRIA, DENTIFRÍCIOS, ESCOVAÇÃO DENTÁRIA.

\section{ABSTRACT}

Oral health education is the dissemination and clarification about the importance of oral health and how to achieve and keep it. The aim of this work is to analyze oral health education through the packages of oral hygiene products for children. For data collection, a form was prepared with questions addressing issues such as the products characteristics, instructions, and when they should be used. Closed answers were analyzed using frequency and the open ones through the technique of keywords and Bardin's method. Thirty one oral hygiene products were analyzed and it was found that only $28.6 \%$ of the toothbrush packages provided information on the brushing technique; tongue and mucous brushing was not mentioned in any of them. As to the amount of toothpaste to be placed on the brush, several answers were obtained. It was concluded that oral hygiene products for children lack standardized educational messages on oral health. Companies should be made aware of the social role of their products.

Keywords: HEALTH EDUCATION, PREVENTIVE DENTISTRY, PEDIATRIC DENTISTRY, TOOTHPASTES, TOOTH BRUSHING. 


\section{INTRODUÇÃO}

A cárie dentária, apesar de apresentar, nas últimas décadas, um declínio acentuado em crianças e adolescentes, é considerada um problema de saúde pública, assim como as periodontopatias. ${ }^{2,3} \mathrm{Em}$ razão dos altos índices de severidade e prevalência desses problemas, é exigido da odontologia um direcionamento de suas atividades para a prevenção. ${ }^{4}$ Diante disso, a motivação e a educação tornam-se ferramentas poderosas para promover a saúde bucal da população e a melhora de sua qualidade de vida. Todavia, devem ser trabalhadas o mais precocemente possível, ${ }^{4,5}$ para que as pessoas adquiram bons hábitos de saúde bucal.

Os programas educativos têm como finalidade promover autocuidados bucais. O público-alvo deve ser cuidadosamente avaliado e orientado de acordo com suas necessidades e dificuldades. Além disso, a motivação deve ser constantemente empregada para que se obtenham mudanças de hábitos na população, consequentemente produzindo multiplicadores de saúde. ${ }^{3}$

As ações de educação e motivação do grupo infantil devem ser direcionadas para a orientação de higienização bucal, especificamente quanto ao uso de instrumentos de higiene, como fio dental, escova de dente, dentifrícios e enxaguatório. Contudo, tais ações são de difícil execução em virtude da divulgação generalizada de mensagens prontas e inadequadas, sob o princípio do marketing financeiro de empresas que não se importam com a eficácia de seus produtos e sua importância. Assim, para que um indivíduo realize uma correta higienização bucal, não basta que tenha condições financeiras para comprar os instrumentos de higiene; é necessário também que receba orientações corretas sobre como utilizá-los. ${ }^{6}$ Quando esse indivíduo é uma criança, os pais são os responsáveis pelos cuidados da higiene bucal, pois até os seis anos de idade a criança não tem maturidade nem coordenação motora para executá-los. , $^{\circ}$

Com relação aos instrumentos de higiene, o fio dental deve ser empregado nos locais em que a papila preenche totalmente o espaço interdentário, pois dessa forma é possível remover adequadamente o biofilme dessas superfícies interproximais, pois são locais em que a escovação não apresenta total eficiência. ${ }^{7}$ No entanto, é necessário que a porção de fio dental que acabou de ser utilizada, e que ficou suja, seja substituída por outra limpa, com o intuito de prevenir o transporte de resíduos e bactérias do dente que acabou de ser limpo para outras faces dentais. Com isso, o fio dental é considerado, juntamente com a escova, o meio mais eficaz de controle mecânico do biofilme dental. 8,9

A escova dental é o objeto mais popular e mais usado para a realização da higiene bucal, tendo a função de desagregar e remover os depósitos microbianos aderidos por meio da ação mecânica das cerdas. Além disso, a escovação é amplamente aceita como um comportamento social, já que é o único instrumento que a grande maioria da população ainda dispõe para fazer o controle do biofilme dental. Garcia et al. ${ }^{9}$ mencionam que a técnica de Bass modificada, que consiste em o paciente colocar a escova entre a gengiva e o dente, formando um ângulo de $45^{\circ}$, vibrando-a nesta posição e girando, com pressão adequada, de cervical para incisal/ oclusal, é considerada adequada. Quando tal técnica é corretamente executada, permite a remoção efetiva da placa bacteriana em torno do sulco gengival e também no restante do dente, colaborando com a diminuição da gengivite ${ }^{8}$ e com o controle da cárie dentária. ${ }^{10}$

Os dentifrícios são produtos que apresentam abrasivos apropriados que, em conjunto com a escova dental, auxiliam na remoção de placas e manchas extrínsecas 
sem ocasionar o desgaste das superfícies dentárias. São componentes presentes nos dentifrícios as diferentes formas de flúor ( $\mathrm{NaF}, \mathrm{Na}_{2} \mathrm{PO}_{3} \mathrm{~F}, \mathrm{MFP}, \mathrm{SnF}_{2}$ ), que são agentes anticáries, agentes umectantes, detergentes, aglutinantes, agentes de sabor, corantes, água, agentes terapêuticos antiplaca, antitártaro, antissensibilidade dentinária e clareadores dentais. ${ }^{12} \mathrm{Em}$ alguns países, como o Brasil, são comercializados dentifrícios especiais para crianças, por apresentarem concentrações menores de flúor. Isto porque os bebês e as crianças pequenas, inadvertidamente, engolem porção considerável do dentifrício durante a escovação (cerca de $30 \%$ ), o que se torna um dos principais riscos associados à ocorrência de fluorose dentária. ${ }^{13}$

A utilização de enxaguatórios bucais promove a retenção do íon flúor na boca após a aplicação destes, proporcionando certo grau de proteção contra o processo carioso por um longo período. É indicada para pacientes que apresentam alto risco para cárie dentária, como crianças que necessitam de cuidados especiais, ou pacientes que recebem radioterapia. Porém, é contraindicada para pré-escolares pelo risco de ingestão. ${ }^{14,15,16}$

Diante do exposto, o objetivo deste trabalho é analisar a educação em saúde bucal por meio das orientações contidas nas embalagens de instrumentos de higiene oral infantil (fio dental, escova de dente, dentifrício e enxaguatório) e sua concordância com a literatura científica e estudar as mensagens de motivação em saúde bucal que nelas existem.

\section{MÉTodos}

O estudo é do tipo documental descritivo e transversal.

Inicialmente, realizou-se uma pesquisa no comércio local nos dois únicos grandes mercados do município de Gurupi (TO) para averiguar a existência e a aquisição de todos os instrumentos de higiene bucal infantil, como escova dental, dentifrício, fio dental e enxaguatório. Houve financiamento próprio dos pesquisadores para a aquisição do material avaliado. Foram comprados todos os instrumentos denominados "de uso infantil", independente da marca comercial.

Os textos constantes nas embalagens foram analisados com o intuito de averiguar suas mensagens/orientações de educação e motivação de saúde bucal, confrontando com as existentes em estudos da literatura científica odontológica presentes nos bancos de dados nacionais e internacionais (BBO, Lilacs, Scielo, Pubmed e Medline) em ciência da saúde pelo site da Bireme (disponível em: $<w w w$.bireme.br>).

A coleta de dados ocorreu por meio da elaboração e do preenchimento de um formulário (Quadro 1) com questões abertas e fechadas sobre o assunto abordado e baseadas nos trabalhos de Fereira et al. ${ }^{5}$, Pedrazzi et al. ${ }^{7}$, Trevisan et al. ${ }^{8}$ e Feitosa et al. ${ }^{11}$. Este foi empregado com o uso de instrumentos de higiene bucal para adultos.

Os dados obtidos foram tabulados utilizando-se o programa EPIINFO 3.2 para Windows e, por meio deste, foi realizado o levantamento de frequências absolutas e relativas das respostas das perguntas fechadas. As orientações e textos existentes em todas a embalagens foram analisados e submetidos à análise de conteúdo preconizada por Bardin, ${ }^{1}$ utilizando a técnica de palavraschave e temática. A primeira técnica consiste na busca de palavras iguais ou semelhantes às contidas na literatura estudada anteriormente. Já a segunda consiste em definir as categorias como rubricas ou classes, as quais reúnem um grupo sob um título genérico. Todos os textos contidos nas embalagens foram lidos para identificar seu contexto. Formou-se uma grade temática de categorias de análise para a leitura transversal de todos os textos, ou seja, cada relato foi lido e classificado segundo as 
categorias registradas. ${ }^{18}$ As análises foram executadas por apenas um pesquisador, o qual fez uma leitura flutuante de todos os textos da literatura científica e das embalagens para, assim, definir as categorias do material pesquisado.

Quadro 1 - Formulário de coleta de dados. Gurupi-TO, 2009.

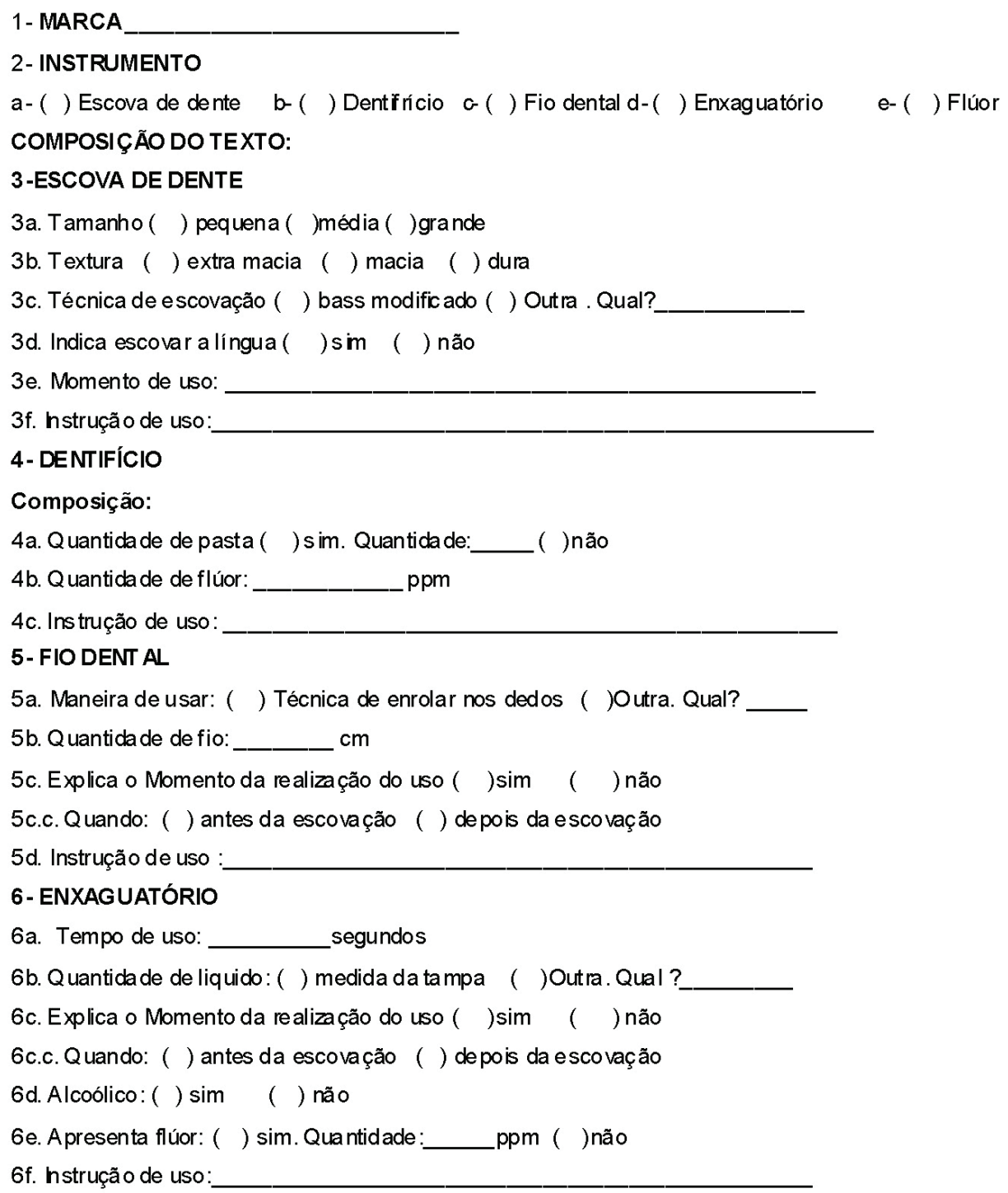

4b. Quantida de de flúor: ppm

$4 c$. Ins trução de uso:

5- FIO DENT AL

5a. Maneira de usar: ( ) Técnica de enrolar nos dedos ( )O utra. Qual?

5b. Quantida de de fio: $\mathrm{cm}$

5c. Explica o Momento da realização do uso ( ) sim ( ) não 5c.c. Quando: ( ) antes da escovação ( ) de po is da esco vação 5d. Instrução de uso :

\section{6- ENXAGUATÓRIO}

6a. Tempo de uso: segundos

6b. Quantida de de liquido: ( ) medida da tampa ( )Outra. Qual ?

6c. Explica o Momento da realização do uso ( ) sim ( ) não

6c.c. Quando: ( ) antes da escovação ( ) de pois da escovação

6d. Alcoólico: ( ) sim ( ) não

6e. Apresenta flúor: ( ) sim. Quantidade: ppm ( )não

6f. hstrução de uso:

Fonte: Fereira et al.5, Pedrazzi et al.7, Trevisan et al.8 e Feitosa et al. 11 


\section{Resultados}

Para o estudo, contabilizaram-se 31 instrumentos de higiene bucal infantil junto ao comércio local, nos principais mercados do município de Gurupi (TO). Desses instrumentos, 14 eram dentifrícios (45,2\%), 8 eram fios dentais $(25,8 \%), 7$ escovas de dentes $(22,6 \%)$ e 2 enxaguatórios $(6,5 \%)$. Todos apresentavam a palavra "infantil" em suas embalagens. Apenas uma embalagem de um fio dental, dentre as oito contabilizadas, apresentava essa especificação, porém decidiu-se contabilizar as demais, pois geralmente os pais acabam comprando apenas um tipo de fio dental para toda a família.

Quase todas as embalagens de fio dental (75\%) relataram que a porção a ser utilizada deveria ter um comprimento de 45 a $50 \mathrm{~cm}$. O mesmo ocorreu quanto à maneira de usálo $(87,5 \%)$, ou seja, enrolar o fio dental nos dedos. Porém, o que chamou atenção foi a especificação nas embalagens sobre 0 momento em que se deve utilizar o fio dental, já que apenas uma delas relatava que seu uso deveria ser após a escovação.

Em relação à escova dental, mesmo o cabo apresentando vários tamanhos, percebe-se que apenas $28,6 \%$ das embalagens mencionavam a descrição do tamanho da cabeça, sendo, no caso, pequeno. Porém, todas eram (100\%) de textura macia.

Sobre a técnica da escovação, somente $28,6 \%$ das embalagens informavam e indicavam a técnica de Bass modificada. Em nenhuma das embalagens foi mencionada a escovação da língua. Já em relação ao momento em que a escova de dente deve ser empregada, $57,1 \%$ mencionavam que seu uso deveria ser realizado após as refeições.

Quanto à instrução de uso da escova dental, observou-se que o principal tema abordado era sua troca em virtude do desgaste (83,3\%). As embalagens estudadas recomendavam a troca a cada três meses (Quadro 2).
Quadro 2 - Distribuição da frequência absoluta e relativa das embalagens de escova de dente infantil, segundo as instruções de uso. GurupiTO, 2009.

\begin{tabular}{|l|l|l|}
\hline Categorias & $\mathbf{n}$ & \%* \\
\hline $\begin{array}{l}\text { Troca da escova - "Troque a sua escova a } \\
\text { cada 3 meses" }\end{array}$ & 5 & 83,3 \\
\hline $\begin{array}{l}\text { Limpeza da escova - "Lavar e secar a escova } \\
\text { após o uso reduzindo assim a proliferação de } \\
\text { bactérias" }\end{array}$ & 2 & 33,3 \\
\hline $\begin{array}{l}\text { Armazenamento - "Guarde a escova } \\
\text { protegendo contra a proliferação de bactérias" }\end{array}$ & 2 & 33,3 \\
\hline
\end{tabular}

* A soma da porcentagem poderá ser maior que 100\%, pois a mesma embalagem poderia apresentar mais de uma instrução de uso. A frequência relativa foi calculada sobre o total de 6 que apresentavam instrução de uso.

Referente às embalagens de dentifrícios obtidas, constatou-se que não havia uma padronização da quantidade de fluoreto, já que seu teor variava desde a que não apresentava flúor $(7,1 \%)$ até a quantidade de 1.100 ppm $(57,1 \%)$. Também se verificou o emprego de diferentes compostos fluoretados, tanto nos dentifrícios como nos enxaguatórios bucais (Gráfico 1).

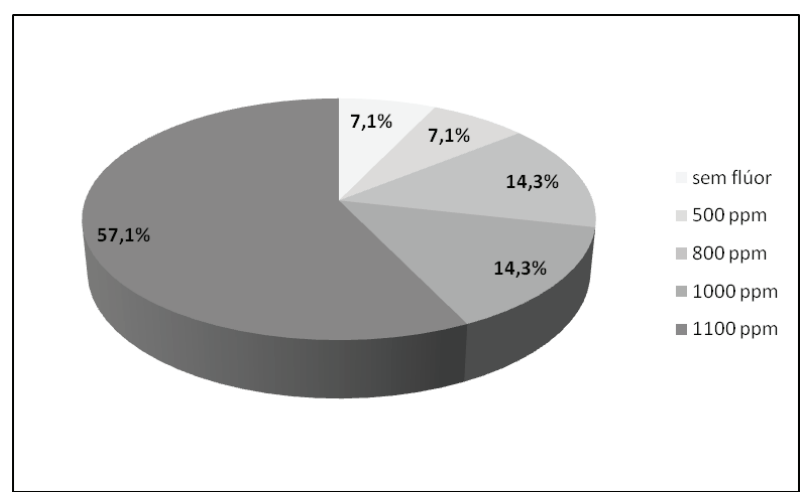

Gráfico 1 - Distribuição percentual das embalagens de dentifrício infantil de acordo com a concentração de flúor empregada no produto. Gurupi-TO, 2009. 
Quanto à quantidade de dentifrício que deve ser colocada na escova de dente, notouse também uma variedade de respostas: $21,4 \%$ das embalagens mencionavam $2 \mathrm{~cm}$ do produto na escova de dente. Já em $14,3 \%$, a sugestão era de uma "quantidade suficiente", prevalecendo uma medida subjetiva, assim como em $21,4 \%$, que informava que deveria ser uma "pequena quantidade". Apenas 7,1\% das embalagens relatavam sobre aplicação de uma gota, já que este era de composição líquida, que permite tal configuração. Grande parte das embalagens $(35,8 \%)$ não apresentava essa informação.

Com relação à instrução de uso nas embalagens, a maioria alertava contra a não ingestão do produto $(71,4 \%)$ e indicava o momento de uso (64,3\%) (Quadro 3).

Quadro 3 - Distribuição da frequência absoluta e relativa das embalagens de dentifrício infantil, segundo as instruções de uso. GurupiTO, 2009.

\begin{tabular}{|l|l|l|}
\hline Categorias & $\mathbf{n}$ & $\%^{*}$ \\
\hline Ingestão - "Não ingerir" & 10 & 71,4 \\
\hline $\begin{array}{l}\text { Momento de uso - “Após as refeições, } \\
\text { ingestão de doces e antes de dormir, ou } \\
\text { conforme orientação do seu dentista" }\end{array}$ & 9 & 64,3 \\
\hline $\begin{array}{l}\text { Tempo de utilização - "Escovando por } \\
\text { um minuto" }\end{array}$ & 3 & 21,4 \\
\hline $\begin{array}{l}\text { Supervisão - "Crianças menores de } \\
6 \text { anos devem ter a supervisão de um } \\
\text { adulto" }\end{array}$ & 2 & 14,3 \\
\hline $\begin{array}{l}\text { Complicações - "Em caso de irritação } \\
\text { procurar um especialista imediatamente” }\end{array}$ & 1 & 7,1 \\
\hline
\end{tabular}

* A soma da porcentagem poderá ser maior que 100\%, pois a mesma embalagem poderia apresentar mais de uma instrução de uso. A frequência relativa foi calculada sobre o total de 14 que apresentavam instrução de uso.

Dos enxaguatórios infantis analisados, nenhum continha álcool e todos apresentavam flúor em concentração de 225 ppm. Ademais, todos explicavam a quantidade de enxaguatório que deveria ser utilizada, ou seja, a medida da tampa do frasco, após a escovação. Apenas uma das embalagens apresentava o tempo de uso, que seria de 60 segundos, e alertava que o paciente deveria evitar comer ou beber por 30 minutos.

Observou-se também nas embalagens, além dos temas abordados, a existência de alguma orientação dirigida às práticas de saúde bucal. Em $67,7 \%$ dessas embalagens foi observada tal orientação, sendo que a grande maioria delas indica a necessidade de visita regular ao cirurgião-dentista $(57,1 \%)$ e de escovação supervisionada por algum adulto $(28,6 \%)$.

\section{Dıscussão}

Dentro do contexto da prevenção para o público infantil, percebe-se que a educação e a motivação devem também ser dirigidas aos pais e responsáveis por essas crianças, uma vez que se tornam responsáveis pela promoção e manutenção da saúde bucal de seus filhos. Aquilante et al., ${ }^{19}$ em seu estudo, perceberam uma forte relação entre o padrão de conhecimento de pais e responsáveis e a motivação e a educação odontológica de seus filhos.

Sobre a utilização do fio dental, Grigoletto et al. ${ }^{20}$ observaram que a maioria das crianças não o utilizava $(67,3 \%)$, sendo que a utilização diária foi ainda menor (9,2\%). A baixa frequência do uso do fio dental pela população deve-se à destituição do real valor deste instrumento, cuja única função atribuída é a de remover restos alimentares e placa dental, que geram desconforto e futuras doenças, como a cárie dentária e doenças periodontais ${ }^{21}$. Já Andrade ${ }^{22}$ enfatiza que os pacientes não têm consciência da importância do uso do fio dental para a manutenção da limpeza dos espaços interdentais. Pesquisas revelaram que o brasileiro consome apenas 
quatro centímetros por ano de fio dental, o que mostra tal desinformação e a falta de motivação e/ou falta de condição financeira para adquirir o produto.

Em relação à técnica de uso do fio dental, observou-se que grande parte das embalagens analisadas $(87,5 \%)$ apresentava a maneira de uso, o que facilita aos pais ou responsáveis o conhecimento da técnica a ser explicada ao filho. Para Garcia et al., ${ }^{6}$ a técnica de uso do fio dental deve ser demonstrada, e o indivíduo precisa treinar sua execução para que sua utilização tenha eficiência. Em seu estudo, a maioria dos pacientes pesquisados $(63,9 \%)$ enrolava o fio dental entre os dedos e $52,4 \%$ trocavam-no quando sujo. Além disso, quase todas as embalagens (75\%) orientavam o uso de um comprimento de fio dental em torno de 45 a $50 \mathrm{~cm}$, porém esse tamanho é recomendado para o uso na dentição permanente. Assim, para o uso infantil, seria importante demonstrar na própria embalagem a quantidade e a maneira de uso para os pais e/ou responsáveis, já que as crianças não apresentam maturidade para empregá-lo.

Quanto ao momento da utilização do fio dental, apenas uma embalagem (12,5\%) mencionava que deveria ser após a escovação. Porém, o momento ideal de sua utilização é antes da escovação, como preconizado por Dotto e Sendryk, ${ }^{23}$ uma vez que a escova atua removendo a placa bacteriana de superfícies livres, as quais são contaminadas por bactérias removidas previamente das regiões interproximais durante a utilização do fio.

Com relação à escova dental, Chiapinotto et al. ${ }^{24}$ enfatizam a necessidade de ensinar o paciente a gostar de limpar seus dentes, executando a tarefa com carinho e dedicação. Em vez da pressa com que se faz, como se a tarefa o "irritasse", deve-se induzi-lo a sentir o sabor e o aroma da limpeza que gradativamente vão tomando conta da boca. Sem dúvida, a correta higienização bucal deve constituir um hábito salutar, o qual é adquirido mediante constante orientação/educação para que o indivíduo possa superar as influências de fatores ambientais, sociais e culturais.

Mais dametade dasembalagensanalisadas $(57,1 \%)$ não apresenta a informação de que a escovação deve ser realizada três vezes por dia e, sim, que se utilize a escova de dente logo após as refeições. A mesma orientação foi encontrada em $73 \%$ das embalagens analisadas por Feitosa et al. ${ }^{11}$ Com isso, promove-se uma mudança de ideia de que só há necessidade de escovar os dentes duas ou três vezes ao dia para a de que se deve realizar a higienização bucal toda vez que o indivíduo alimentar-se. Em estudos ${ }^{25,26}$ foi observado que a maioria dos entrevistados escova os dentes três vezes por dia e que as crianças devem escovar duas vezes ao dia com dentifrício fluoretado e com supervisão de adultos.

Em relação à técnica de Bass modificada, apenas $28,6 \%$ das embalagens apresentavam e explicavam-na. Mas, segundo Trevisan et al., ${ }^{8}$ esta técnica, apesar de complexa para a maioria das crianças, é bastante enfatizada como correta. ${ }^{9}$ Mas a técnica habitual, ou a de esfregaço com o fio dental, é a mais recomendadas.

Diante das informações obtidas, há necessidade de maior conscientização dos pais sobre essa responsabilidade; apesar de eles acharem que os dentes de seus filhos devem ser escovados duas vezes ao dia, nem sempre o fazem na prática, o que se verifica na falta de supervisão da escovação das crianças, o que reduz sua qualidade, ${ }^{5,27}$ seja pelas embalagens, profissionais da saúde etc., até porque apenas $28,6 \%$ de todas as embalagens apresentavam que a escovação infantil deveria ser supervisionada.

A maioria das embalagens de escova de dente $(83,3 \%)$ enfatizava que a troca deveria ocorrer a cada três meses. Dados semelhantes $(87 \%)$ foram encontrados no estudo de Feitosa et al., ${ }^{11}$ como recomendado pelas autoridades 
de saúde bucal. Entretanto, sabe-se que no país o consumo per capita de escova dental é considerado baixo, pois o brasileiro costuma comprar uma escova a cada 17 meses. Sabese que o uso compartilhado da escova pode transmitir inúmeras doenças infecciosas, virais e parasitárias. ${ }^{20}$ Isso pode ocorrer, possivelmente, pela falta de informação e educação dos pacientes a esse respeito. Diante disso, há a necessidade de profissionais, veículos de comunicação e guias de prevenção reforçarem a importância da escovação correta e da troca periódica da escova, recomendarem o não compartilhamento da escova e o seu correto armazenamento e transporte com as cerdas devidamente protegidas, pois estas entrarão em contato com a cavidade bucal. Esses assuntos foram abordados por apenas $33,3 \%$ das embalagens pesquisadas.

O uso de dentifrício é um meio importante de motivação para a escovação. Porém, Parizotto et al. ${ }^{28}$ verificou que não há diferença significativa no controle mecânico do biofilme dental em relação ao uso ou não do dentifrício. Nota-se que o tamanho de dois centímetros de dentifrício, conforme mencionado em 21,4\% das embalagens, é considerado excessivo. Todavia, a quantidade usada por escovação varia entre os estudos e poucos a associam ao tamanho da escova usada pela criança e a outros hábitos da escovação. Isto seria importante, já que ela ingere e absorve grande parte da quantidade de dentifrício, o que pode provocar fluorose dentária. É prciso lembrar que crianças com idade pré-escolar apresentam maior risco de desenvolvê$\mathrm{la}^{14,15,16}$. Vilhena et al. ${ }^{29}$ perceberam em seu estudo que, quanto maior a idade da criança, maior a quantidade de dentifrício colocada na escova. Isso demonstra a necessidade do uso consciente do dentifrício, até porque corresponde diretamente ao uso racional do flúor que compõe esse instrumento.

Quanto aos enxaguatórios bucais analisados, nenhum continha álcool e todos apresentavam flúor em sua composição em uma concentração de 225 ppm. Seria de suma importância que os enxaguatórios bucais analisados apresentassem flúor, pois é uma forma de prevenção da cárie, principalmente para as crianças em idade escolar, que apresentam maior risco de desenvolver a fluorose. Estudos têm avaliado a questão erosiva dos enxaguatórios, pois, em decorrência do $\mathrm{pH}$ ácido, podem promover erosão dental. Entretanto, a presença de flúor na composição e o meio ácido podem facilitar sua adesão e a deposição de fluoreto de cálcio na estrutura dental. ${ }^{30}$

Com relação às orientações dirigidas a práticas de saúde bucal, observou-se que $67,7 \%$ das embalagens analisadas prestaram tais esclarecimentos e destas, a grande maioria indicou visita regular ao cirurgiãodentista $(57,1 \%)$ e escovação supervisionada por algum adulto $(28,6 \%)$.

\section{Conclusões}

Diante dos dados obtidos e trabalhos analisados, existe uma grande diversidade de mensagens/orientações sobre educação e motivação em saúde bucal nos produtos de higienização para o público infantil, que, muitas vezes, não correspondem com o que é pregado na literatura científica. Assim, faz-se necessária a conscientização das empresas quanto ao papel social de seus produtos, principalmente em relação às crianças, a fim de que apresentem e mantenham hábitos de higiene bucais corretos para a vida toda.

\section{REFERÊNCIAS}

1. Bardin L. Análise de conteúdo. Lisboa: 70; 1994.

2. Brasil. Ministério da Saúde. Secretaria de Atenção à Saúde. Secretaria de Vigilância em Saúde. SB Brasil 2010: Pesquisa Nacional de Saúde Bucal: resultados principais / Ministério da Saúde. Secretaria de Atenção à Saúde. Secretaria de Vigilância em Saúde. Brasília: Ministério da Saúde; 2012. 
3. Meneghim MC, Esmeriz CEC, Vilas-Boas $\mathrm{P}$, Meneghim ZMP, Pereira AC. Impacto de programas educativos sobre condições bucais de escolares de 6 e 7 anos em duas escolas municipais do interior do Estado de São Paulo/ Brasil. Arquivos em Odontologia. 2012 Jan-Mar; 48(1): 40-6.

4. Ribeiro DG, Dovigo LN, Silva SRC. Avaliação de um método educativo em saúde bucal aplicado em escolares de ensino público. Arquivos em Odontologia. 2009 Jul-Set; 45(3): 154-9.

5. Fereira JMS, Silva SF, Aragão AKR, Duarte RC, Menezes VA. Conhecimento de pais sobre saúde bucal na primeira infância. Pediatr Mod. 2010 Nov-Dez; 46(6): 224-30.

6. Garcia PPNS, Corona SAM, Garcia D. Educação do paciente: aplicação do método audiovisual na instrução do uso do fio dental. Periodontia. 2003 Jan; 13(7): 26-30.

7. Pedrazzi V, Sato S, Matos MGC, Lara EH, Panzeri $H$. Tongue-cleaning methods: a comparative clinical trial employing a toothbrush and a tongue scraper. J Periodontol. 2004 Jul; 75(7): 1009-12.

8. Trevisan EAS, Toledo BEC, Raveli DB, Cordeiro RCL, Mendes AJD. Estudo clínico do comportamento de técnicas de escovação dental e suas associações sobre as condições gengivais. Rev Bras Odontol. 1991 Jul-Ago; 48(4): 46-8.

9. Garcia PPNS, Rodrigues JA, Santos PA, Dinelli W. Avaliação clínica do comportamento de higiene bucal em adultos. Rev Odontol. Unesp 2001 Jul-Dez; 30(2): 161-71.

10. Kidd EAM, Fejerskov O. Cárie dentária - a doença e seu tratamento. 2 ed. São Paulo: Editora Santos; 2005.

11. Feitosa NB, Martins CC, Chalub LLF, Vale MPP, Paiva SM. Avaliação da apresentação comercial de escovas dentais disponíveis no Brasil. Rev Odonto Ciênc. 2008; 23(1): 77-81.

12. Camargo IM, Saiki M, Vasconcelos MB, Avila DM. Abrasiveness evaluation of silica and calcium carbonate used in the production of dentifrices. J Cosmet Sci. 2001 Mai-Jun; 52(3): 163-7.

13. Cury JA, Oliveira MJ, Martins CC, Tenuta LM, Paiva SM. Available fluoride in toothpastes used by Brazilian children. Braz Dent J. 2010; 21(5): 396-400.

14. Pessan JP, Silva SMB, Buzalaf MAR. Evaluation of the total fluoride intake of 4-7-year-old children from diet and dentifrice. J Appl Oral Sci. 2003 Jun; 11(2): 150-6.

15. Lima YBO, Cury JA. Ingestão de flúor por crianças através da água e dentifrício. Rev Saúde Pública. 2001; 35(6): 576-81.

16. Brasil. Ministério da Saúde. Secretaria de Atenção à Saúde. Guia de recomendações para o uso de fluoretos no Brasil. Departamento de Atenção Básica: Brasília: Ministério da Saúde; 2009.

17. American Academy of Pediatric Dentistry. Guideline on caries-risk assessment and management for infants, children, and adolescents. Pediatr Dent. 2011; 34(6): 118-25.

18. Gonçalves ER, Verdi MIM. Os problemas éticos no atendimento a pacientes na clínica odontológica de ensino. Ciênc Saúde Coletiva. 2007 Mai-Jun; 12(3): 755-64.

19. Aquilante AG, Bastos JRM, Sales Peres SHC, Leal RB, Higa AM. Análise do nível de educação odontológica dos pais/responsáveis de escolares da $3^{\mathrm{a}}$. série do $1^{\circ}$. grau e sua relação na motivação e educação odontológica de seus filhos. Rev Odontol UNICID. 2002 JanAbr; 14(1): 25-34.

20. Grigoletto JC, Watanabe MGC, Mestiner $\mathrm{Jr}$ W, Bregagnolo JC.Higiene Oral e uso compartilhado de escova dental. Rev Odontol Unesp. 2006 Abr-Jun; 35(2): 175-81.

21. Vinha PP, Bignelli P, Mansor PRG, Spinola LF, Vinha D. O uso do fio dental junto ao público. Rev Paul Odontol. 1993 Mar-Abr;15(2): 38-42.

22. Andrade $M$. O nó do mercado. Rev $A B O$ Nacional. 1996; 4: 14-8.

23. Dotto CA, Sendryk WR. Atlas de higienização bucal. São Paulo: Panamed; 1982.

24. Chiapinotto GA, Meller D, Santos FB. Meios mecânicos de limpeza dos dentes: avaliação de indivíduos de uma clínica privada. RGO. 1998 Jul-Set; 46(3): 142-4.

25. Esteves SRR, Milanezi LA, Carvalho LB, Garcia VG. Avaliação das marcas das escovas dentárias, do seu tempo de uso e da frequência de escovação diária dos alunos ingressantes em 1998, no curso de ciências Odontológicas da Unimar - São Paulo, Brasil. Rev Cienc Odontol. 2002 Jan-Dez; 5(5): 43-7.

26. American Academy of Pediatric Dentistry Guideline on Fluoride Therapy. Am Acad Ped Dent. 2011; 34(6): 162-65.

27. Bardal PAP, Olympio KPK, Bastos JRM, Henriques JFC, Buzalaf MAR. Educação 
e motivação em saúde bucal: prevenindo doenças e promovendo saúde em pacientes sob tratamento ortodôntico. Dental Press J Orthod. 2011 Mai-Jun; 16(3): 95-102.

28. Parizotto SPCOL, Rodrigues CRMD, Singer JM, Sef HC. Effectiveness of low cost tooth brushes, with or without dentifrice, in the removal of bacterial plaque in deciduous teeth. Pesqui Odontol Bras. 2003; 17(1): 17-23.

29. Vilhena FV, Sales-Peres SHC, Caldana ML, Buzalaf MAR. Novo protocolo para as ações de saúde bucal coletiva: padronização no armazenamento, distribuição e uso do material de higiene bucal. Ciênc \& Saúde Coletiva. 2008 Dez; 13(Suppl 2): 2097-103.

30. Heimer MV, Cruz RA. A deposição de fluoreto de cálcio no esmalte dentário humano in vitro após tratamento com soluções fluoretadas para bochechos. Rev Bras Odontol. 1995 Jan-Fev; 52(1): 9-14.

Submetido em: 25-1-2013

Aceito em: 9-5-2013 